\title{
De Deliberatibus Disputandum Est: A Response to Jürg
}

\section{Steiner}

\section{Gerald Schneider}

Department of Politics and Management, University of Konstanz, Box D 86, D-78457

Konstanz, Germany.

E-mail: gerald.schneider@uni-konstanz.de, Fax: +49-7531-882774 


\title{
De Deliberatibus Disputandum Est: A Response to Jürg
}

\section{Steiner}

\begin{abstract}
This article takes issue with Steiner's polemic against the usage of "deliberation" in rational choice scholarship. I show that i) the reproach that rationalists do not allow for preference change is mistaken; ii) that Steiner does not sufficiently distinguish between normative and positive contributions and iii) that he shields his preferred model against systematic comparisons with strategic models of deliberation. In my view, we need more competing model evaluations rather than misleading attacks against imagined heretics.
\end{abstract}

Keywords: Deliberation, Rational Choice, Strategic Behaviour, Preference change 
Before I speak, I have something important to say.

Groucho Marx

\section{Introduction $^{1}$}

In a spirited polemic against the rational choice usage of the concept of deliberation in general and a contribution by Austen-Smith and Feddersen (2006) in particular, Jürg Steiner (this issue) reminds us of the danger that we frequently overstretch the applicability of a particular idea. I full-heartedly agree that self-aggrandizement through overstating the importance of one's own ideas is still often enough a problem in our discipline. I nevertheless believe in line with Robert Goodin (this issue) that this is a minor problem. The more fundamental challenge in the study of deliberation is the lack of a systematic model evaluation. Such endeavours require that we compare the predictive accuracy of what Steiner describes as the rationalist approach to deliberation and of what he considers to be its proper alternative. The consequence of the failure to contrast competing explanations systematically against each other is what Popperians call "self-immunization" and hence the tendency to shield the preferred hypothesis against contrasting evidence (e.g. Albert, 1968).

The lack of a clearly specified alternative explanation is present in both quantitative and qualitative work. In the former domain, the theory-free search for "significant" findings has its visual expression in star-loaded regression tables which report statistical results with sometimes little substantive importance - the ill-reputed "galaxies" which we all too often encounter even in the best journals. As Achen $(2002,2005)$ has forcefully argued, we cannot trust such "garbage can regressions" because we do not really know whether the effect of a variable of theoretical interest represents the "true" impact or is just due to the inclusion of a theoretically irrelevant "control" factor in the regression. It is no wonder that he has called for regression equations that closely correspond to the theoretical model they are supposed to represent. As our theories are not yet well developed, regressions should then, in his view, follow the "rule of three" and only include a limited number of explanatory concepts. 
In qualitative research, the reliance on buzzwords instead of clearly demarcated causal mechanisms has also often the consequence that the predictive accuracy of a particular approach cannot be properly evaluated. Moravcsik (2001) for instance criticizes constructivist scholars whose hypotheses are indistinguishable from traditional rationalist explanations, rendering a proper model comparison impossible.

In the empirical study of deliberation, the early usage of Elster's (1992) ideal types of "bargaining" and "arguing" has led to an either-or-discussion in which the presence of a specific decision making mode is rather claimed then properly shown (Schneider, 2008). The contributions by Jürg Steiner and his colleagues (Steiner et al., 2005) has fortunately moved the field decisively away from these inconclusive and unwieldy debates over the significance of deliberation in democratic politics and international relations.

Steiner's (2008) criticism of Feddersen and Pesendorfer (2006) is, however, a step back in the discussion through his claim that the inclusion of strategic behaviour in a model of deliberation overstretches the applicability of this very concept. As any model of social behaviour should be checked from an individualistic perspective for its compatibility with the incentives and beliefs of the actors, Steiner's rejection of the usage of strategic reasoning renders it impossible to compare his implicit communitarian model against competing rationalist models.

This comment will show that Steiner has chosen the wrong target to hone home his warning against the overstretching of "deliberation" as an analytical concept. To this end, I will first briefly outline the wider research tradition into which the Austen-Smith and Feddersen (2006) model has to be placed. I will also correct two facets in Jürg Steiner's comment - his denial of the possibility that rationalist models allow for preference change and his neglect in properly distinguishing between normative and positive contributions to the field. 


\section{Rationalist Models of Deliberation}

Rationalist models, by and large, fall into two categories. The first one stands in the shadow of the seminal contributions by Nobel awardees Arrow and Sen and addresses the problem of how individual incentives translate into collective choice. One of the key findings in this literature is the Gibbard-Satterthwaite theorem. This mathematical result shows that any collective that faces a simultaneous decision over three or more candidates or policy options will experience strategic voting. This means that some individuals will always opt for their second-preferred option in order to prevent that the worst alternative is adapted. Such scheming behaviour can result in final outcomes which do not represent the option or candidate with the largest number of supporters. Democratic decision do therefore not necessarily correspond to the will of people.

The second and lesser know tradition in the social choice literature assumes that preference heterogeneity is minimal or can even be completely neglected; it rather focuses on the aggregation of individual beliefs into collective ones. While the first approach has the Pareto criterion as the ultimate arbiter to judge over the optimality of a collective decision, the second approach mainly uses information efficiency as a benchmark to evaluate a specific outcome. We need accordingly to judge whether a collective decision was correct or erroneous. In contrast to the literature on interest aggregation, the collective decision making process is thus not about which political position carries the day, but rather which "vision" becomes socially acceptable. This is important with regard to jury trials as well as panels of scientists who have different beliefs about the state of the world.

Austen-Smith and Feddersen (2006) contribution belongs to the second research tradition and builds on one of the canonical starting point of rational choice theory within this area of research, the Condorcet Jury Theorem (CJT). The CJT assumes in its traditional setup that i) the average competence of the individuals, who belong to a committee making a collective decision, in recognizing the "true" state of the world exceeds 0.5 , ii) that their 
judgments are independent of each other and iii) that they "vote" for one state of the world in a sincere fashion. Based on this optimistic view of social interactions, the original version of the CJT leads to two main hypotheses. A first result is that the competence of a group in recognizing the true state of the world is larger than the average individual competence. Second, this collective capability approximates 1 if the size of the committee grows. Large electorates would accordingly be able to reach almost "correct" decisions in situations where voters share the same fundamental preference, but receive different information about the state of the world. ${ }^{2}$

Marquis de Condorcet (1785[1972]) originally believed that this result could reconcile the pessimism that his other fundamental result - the possibility of decision cycles in the event that some group member has an intransitive preference profile - implied. Long before Habermas and other contemporary political philosophers, he believed that deliberation might be a process that helps a society to overcome the anomalies that such central decision making rules like majority voting might entail in the aggregation of interests. ${ }^{3}$ The optimistic viewpoint has, however, experienced some major blows. Berg (1993) showed for instance that the collective competence might be smaller than the one of the average individual if one of the underlying assumptions is violated and the individual beliefs are correlated. Such correlations can occur if the decision making group is hierarchically structured and if the judgment of some "opinion leader" bears its mark on the decision of other individuals. Furthermore, the collective does not increase its competence if the number of marginally competent individuals (p slightly larger than 0.5) increases (Paroush, 1998).

The main objection towards the traditional version of the CJT is, however, that it implicitly assumes, like Jürg Steiner's comment implies, sincere voting and thus non-strategic behavior in a social interaction. If we move to a strategic context where individual incentives can be in opposition to the collectively optimal, sincere voting is generally not a Nash 
equilibrium. The collective ability to choose the "correct" solution is therefore in some occasions smaller than the average individual one. Majority voting on the "correct" solution can consequently be worse than the choice by an individual who acts alone (Austen-Smith and Banks, 1996). The main assumption behind this counterintuitive result is that the signals that committee members receive about "reality" are at least partly private. At least two reasons justify this assumption. First, the way in which experts process messages about the state of the world differs from one committee member to another. Second, the communication into which experts might engage with each other is never completely free of misunderstandings and errors. Based on this result, Austen-Smith and Banks (1996: 44) caution against general recommendations on optimal decision making rules and write: "...the appropriateness of majority rule (or, for that matter, any voting rule) in generating "good" collective outcomes will depend on the details of the situation of concern" (ibid.: 44).

Feddersen and Pesendorfer $(1998,1999)$ flesh out further institutional implications of the strategic version of the CJT. They show that the likelihood of a collective error depends on the voting rule $\mathrm{V}$ defined as a fraction of the committee size, ranging from dictatorship $1 / \mathrm{n}$ over simple majority $\mathrm{n} / 2$ (or rather the smallest integer that exceeds this threshold) to unanimity $\mathrm{n}$. Their results suggest a nonlinear relationship between $\mathrm{V}$ and the probability that the committee commits both type 1 or type 2 errors (that is, rejects or accepts the null hypothesis in situations in which the state of the world would imply that the contrary is correct).

The hypothesis that a curvi-linear relationship between the decision making quorum and the error probabilities exists receives empirical support in the experiments by Guarnaschelli et al. (2000). Their evidence implies that unanimity decision making in juries might lead to erroneous results, but less frequently than predicted in the models. Although we do not yet possess another confirmation of the strategic model of the CJT, the qualifications 
of the unanimity rule are important. Feddersen and Pesendorffer (1998: 31) derive such policy insights from their work and write: "When jurors vote strategically, the unanimity rule results in a strict positive probability of both acquitting the guilty and convicting the innocent."

This result casts some strong doubts on the praise that the unanimity ruled typically obtains in the public choice literature. Buchanan and Tullock (1962) as well as their adherents suggest that unanimity voting is the optimal decision making rule, at least for constitutional choices and decisions on the provision of public goods. Yet, as Feddersen and Pesendorfer demonstrate convincingly, if the informative value of a decision making rule is the only matter under consideration, qualified majority is preferable to unanimity voting.

Allowing for deliberation prior to voting, Coughlan (2000) qualifies the result that collective errors are a non-linear function of $\mathrm{V}$. He shows that some extensions of the results by Feddersen and Pesendorfer save the unanimity rule in Jury decisions. Unanimity voting beats majority voting if a jury faces the risk that a mistrial occurs - no unanimous decision is reached - or if its members are, as indicated, able to communicate their private information. This highlights that deliberation might help to improve the informational efficiency of certain decision making rules and that majoritarian decisions are only to be preferred in the event that no real discourse on the content of a new policy measure or research hypothesis takes place. Guarnaschelli et al. (2000) support this claim and thus show empirically that deliberation in situations where individuals act strategically can (but must not) make a difference.

Austen-Smith and Feddersen's (2006) article studies whether Coughlan's (2000) inclusion of deliberation into the strategic version of the CJT is generalizable. Their main result is again to show that majority rule is preferable over unanimity rule insofar as it entices more "truth telling" than the latter decision making rule. Their contribution to the normative literature on deliberation is to uncover a major problem in the widespread insistence in the literature - it also implicitly appears in Steiner's comment - that that personal interests and 
biases that possibly violate the common purpose should be stated before the discussions within a group begin. As Austen-Smith and Feddersen, conversely, show, the inclusion of strategic action and incomplete information are sufficient to turn Steiner's and many other communitarian arguments upside down: The sincere revalation of one's personal predisposition that is so important in the Habermasian logic is thus, in other words, not necessarily a good thing!

Jürg Steiner's objection against the usage of strategic reasoning could easily be resuscitated if individuals did not behave strategically in situations of low conflict and hence if Nash behavior is of no empirical relevance here. The already mentioned experiments conducted by Guarnaschelli et al. (2000), however, rather show that strategic behavior matters even in situations where we could sensibly imagine that other-regarding behavior dominate selfish considerations. Although some current experiments in economics stress the importance of altruistic and other-regarding behavior, Binmore (2007) rightly points out that aggregate outcomes often move closer to the game-theoretic predictions in many situations once the monetary incentives are made more attractive. In my view, refusing to consider strategic behavior a priori amounts to saying that such fundamental results as the GibbardSatterthwaite theorem or, in the domain of belief aggregation, the research tradition inaugurated by Austen-Smith and Banks (1996) and continued by Austen-Smith and Feddersen (2006) are of no practical relevance. The contrary seems to be the case, as Gabel and Shipan (2004) convincingly advocate with regard to drug trials. What is more, the rejection of a model based on its assumption borders on censorship or on the hapless attempts to suppress rationalist thinking: “...I know of at least one case in which a university senate was asked to ban the teaching of rational choice theory on the ground that it was immoral", writes Ken Binmore (2007: 21, exclamation mark suppressed) illustratively. 


\section{Too much Habermas, too little strategic action and a plea for alternative theory testing}

One of the outworn reproaches against rational choice reasoning is that game theoretic models do not allow the researcher to consider episodes of endogeneous preference change. Jürg Steiner, unfortunately, buys into this notion and writes that the "ultimate preferences" are never changed so that a socially preferable option cannot be materialized. ${ }^{4}$ The main counterargument against calls for models in which the preferences of the actors change is that one needs to hold one element in a theoretical explanation constant in order to explain anything at all. In most cases, this will be the preferences that are assumed to be given for a specific interaction. Furthermore, there are already rationalist models of preference change, not the least Becker's (1996) model of addiction or Benabou and Tirole's (2006) attempts to reconcile psychology and economics.

The kind of preference change that Jürg Steiner has in mind is probably more limited in theoretical ambition. He seems to assume that strategic voting stands in the way of getting convinced by an argument by the other side and to finally opt for this position. This is perfectly possible within the strategic version of the CJT, as Goodin (this issue) shows. Yet, the contrary is also possible - that someone, given her incentives and information, does not tell the truth. Avoiding the possibility ex cathedra that people might be liars transforms Jürg Steiner's implicit model of deliberation into a purely normative one with little empirical relevance for the behavior of "real" people.

Admittedly, it is often very difficult to clearly distinguish between "normative" and "positive" models. The literature to which Steiner alludes at the theoretical level to disqualify the rationalist study of deliberation is normative. We can, however, not assess a particular model, be it of positive or normative vintage, if we do not come up with a sensible benchmark. In other words, if we are dealing with an idealized model of communication like the Habermasian one, we need to specify the conditions under which such a vision can be reached and what factors stand in its way. From an individualist viewpoint, conflicting 
preferences and information levels might be key hindrances and, as a consequence, the strategic behavior of the individuals belonging to a group. One way to study deliberation then is by defining axiomatically what deliberation entails and to evaluate with the help of game theory or other analytical tools whether and where power-free social communication is possible. This is what rationalists do since decades with considerable success, and AustenSmith and Feddersen (2006) have added an important contribution to this tradition.

To sum up, the main contribution of Jürg Steiner's response to Austen-Smith and Feddersen (2006) is his reminder that we should be careful in delineating the domain in which a particular theory is applicable. All contributors to this forum certainly agree with this warning. We disagree, however, over the way in which Professor Steiner tries to avoid the over-stretching of the concept of deliberation. In my view, Jürg Steiner falls into the trap of not taking individual incentives and thus Nash behavior seriously enough. If he would explicitly state how his model differs from a strategic model of deliberation, a comparison of competing predictions would be possible. The neglect to consider alternative explanations leads to another problem, which, in my view, is much more severe than the danger of overstretching - the risk of self-immunization one's own research against competing explanations. In the classic Popperian view, any research tradition that is not open for attempts of falsification risk to build up a myth or a fair weather theory which only holds under some and, in most cases, trivial conditions. Similarly over-optimistic conclusions can be drawn from a mathematical model which is shielded against attempts to probe its generalizability.

The text by Jürg Steiner, who is an inspiring colleague and wonderful mentor since more than 15 years, then teaches us three lessons which were already partly known among the Romans two millennia ago: First, we should not discuss tastes and develop models in which everything changes. Hence, we need to keep something fixed in order to explain anything at all, and the constant will be in most modeling enterprises the preference of the actors. The second lesson is that normative theories should also consider how real people behave and 
show what sort of strategic behavior endangers the provision of the common good. Third, and in this context more importantly, however, we need to talk about specific models and should refrain from dismissing a model just because we do not like the particular assumptions on which it is based or because they seem to be in opposition to the received wisdom within a particular area of research. To rephrase the saying that that "there is no disputing of taste" I would claim: de deliberatibus disputandum est!

\section{References}

Achen, C. H. (2002) 'Toward a New Political Methodology: Microfoundations and ART', Annual Review of Political Science 5: 423-450.

Achen, C. H. (2005) 'Let's Put Garbage Can Regressions and Garbage Can Probits Where They Belong', Conflict Management and Peace Science 22: 327-350.

Albert, H. (1968) Traktat über die kritische Vernunft, Tübingen: Mohr.

Austen-Smith, D. and Banks, J. S. (1996) 'Information Aggregation, Rationality and the Condorcet Jury Theorem', American Political Science Review 90(1): 34-45.

Austen-Smith, D. and Feddersen, T. J. (2006) 'Deliberation, Preference Uncertainty and Voting Rules', American Political Science Review 100(2): 209-218.

Becker, G. S. (1996) Accounting for Tastes. Cambridge, Mass.: Harvard University Press.

Benabou, R. and Tirole, J. (2006) 'Incentives and Prosocial Behavior', American Economic Review 96(5): 1652-1678.

Berg, S. (1993) 'Condorcet's Jury Theorem, Dependency among Jurors', Social Choice and Welfare 10: 87-96.

Binmore, K. (2007) Does Game Theory Work: The Bargaining Challenge, Cambridge, Mass.: MIT Press.

Buchanan, J. M. and Tullock, G. (1962) The Calculus of Consent, Ann Arbor: University of 
Michigan Press.

Condorcet, J. A. N. de Caritat de Condorcet, Marquis de (1785[1972]), Essai sur l'Application de l'Analyse à la Probabilité des Decisions Rendues à la Pluralité des Voix, New York: Chelsea Publ. Co. (Original: Paris: Imprimerie Royale).

Coughlan, P. J. (2000) 'In Defense of Unanimous Jury Verdicts: Mistrails, Communication and Strategic Voting', American Political Science Review 94: 375-393.

Elster, J. (1992) 'Arguing and Bargaining in the Federal Convention and the Assemblée Constituante', in R. Malnes and Arild Underdal (eds.) Rationality and Institutions: Essays in Honour of Knut Midgaard, Oslo: Scandinavian University Press, pp. 13-50.

Feddersen, T. and Pesendorfer, W. (1998) 'Convicting the Innocent: The Inferiority of Unanimous Jury Verdicts', American Political Science Review 92: 23-35.

Feddersen, T. and Pesendorfer, W. (1999) 'Perspectives - Elections, Information Aggregation, and Strategic Voting', Proceedings of the National Academy of Sciences of the United States of America. 96(1): 10572-10574.

Gabel, M. J. and Shipan, C. R. (2004) 'A social choice approach to expert consensus panels'; Journal of Health Economics 23(3): 543-564.

Goodin, R. (2008) ‘Deliberative Lies’, European Political Science

Grofman, B. and Feld, S. (1988) 'Rousseau's General Will: A Condorcetian Perspective', American Political Science Review 82(2):567-576.

Guarnaschelli, S., McKelvey, R. D. and Palfrey, T. R. (2000) 'An Experimental Study of Jury Decision Rules', American Political Science Review 94(2): 407-423.

Lada, K. K. (1992) 'The Condorcet Jury Theorem, Free Speech, and Correlated Votes', American Journal of Political Science 36: 617-634.

McLean, I. and Hewitt, F. (1994). Condorcet: Foundations of Social Choice and Political Theory, Aldershot: Elgar.

Moravcsik, A. (2001) 'Bringing Constructivist Theories of the EU out of the Clouds: Have they 
Landed Yet?', European Union Politics 2(2): 231-249.

Paroush, J. (1998) 'Stay Away from Fair Coins: A Condorcet Jury Theorem', Social Choice and Welfare 15(1): 15-20.

Schneider, G. (2008) 'Qui a Peur de John Nash? Le choix rationnel dans les relations internationals et la science politique allemande’, in S. Saurugger and M. Delori (eds.) Pour un débat sur les apports et limites du choix rationnel en science politique, Paris: Economica.

Steiner, J., Bächtiger, A., Spörndli, M. and Stteenbergen, M. R. (2005) Deliberative Politics in Action. Analyzing Parliamentary Discourse, Cambridge University Press.

Steiner, J. (2008) 'Concept Stretching: the Case of Deliberation', European Political Science. Stigler, G. J., Becker, G. S. (1977) 'De Gustibus Non Est Disputandum', American Economic Review 67(2): 76-90.

Young, H. Peyton (1988) 'Condorcet's Theory of Voting', American Political Science Review 82(4): .

\begin{abstract}
About the author
Gerald Schneider is Professor of Political Science at the University of Konstanz, Germany, where he has held the International Relations Chair since 1997. He is also Executive Editor of European Union Politics. His main research interests are in the areas of political decision making, regional integration and political conflict.
\end{abstract}

\title{
Notes
}

\footnotetext{
${ }^{1}$ The title of this article draws on the seminal article by Stigler and Becker (1977).

${ }^{2}$ The rediscovery of the CJT is largely due to Duncan Black. See Grofman and Feld (1988), Young (1988) and Lada (1992).
} 
${ }^{3}$ Condorcet was also a politician, architect of the "Girondain constitution" and friend of Thomas Jefferson and other U.S. politicians. McLean and Hewitt (1994) discuss Condorcet's (1785[1972]) contributions to the social choice literature in more detail.

${ }^{4}$ The problem of whether or not individuals change their preferences endogenously or not is closely linked to the consistency criterion that rational choice modellers impose on their actors- the transitivity condition according to which the preference orders of individuals remain the same when they face equivalent decision making problems. The only exception to this sensible rationality criterion I know of is mirrored in the erratic behaviour of former Bavarian Prime Minister Edmund Stoiber who had in 2005 major difficulties in figuring out whether he should go to Berlin as a "super minister", hang on in Munich as "father" of "his" Land or retire to his provincial residence in Wolfratshausen. To the amusement of the wider audience and to the distress of his supporters, the changing preferences of Stoiber revealed severe forms of intransitivity. It should be added sadly that his more or less forced retirement has made it much harder to explain the basics of (non)rational behaviour in a German classroom through illustrative examples. 